\title{
Treatment of pneumothorax by simple aspiration
}

\author{
AAD HAMILTON, GJ ARCHER \\ From Stepping Hill Hospital, Stockport, Cheshire
}

ABSTRACT Ten patients with pneumothoraces were treated by simple aspiration. Treatment was successful in seven after single or multiple aspirations. Only one of these pneumothoraces has recurred and surgical treatment was then required.

It is customary to treat patients with pneumothoraces by insertion of an intercostal tube connected to an underwater seal drain. During the last year, however, we have treated these patients by simple aspiration.

\section{Method}

All patients with an uncomplicated pneumothorax requiring treatment who were admitted to this hospital from April 1982 to February 1983 were included in the study. Treatment was deemed necessary if more than $30 \%$ of the lung collapsed or if there were continuing symptoms such as pain or dyspnoea. Complicated pneumothoraces (for example, with tension) were excluded from the study.

After the diagnosis had been confirmed radiologically, informed consent to the procedure was obtained. A site was chosen either in the second intercostal space anteriorly, in the mid-axillary line laterally, or below the scapula posteriorly. An aseptic technique was used and the skin cleaned in the usual manner. Local anaesthetic was injected at the site and after time had been allowed for this to work a 16 gauge intravenous cannula with small syringe attached was inserted through the chest wall. The needle was extracted from the cannula and a "three way tap" connected. To the other two parts of the tap were connected a $60 \mathrm{ml}$ syringe and a length of plastic tubing, the other end of which was placed in a jug of sterile water. The air was then gently aspirated from the pneumothorax and expelled under water. This was to ensure that the air was going in the right direction through the tap and that a tension pneumothorax was not being created. The total volume of air aspirated was recorded. If re-expansion

Address for reprint requests: Dr GJ Archer, Stepping Hill Hospital, Stockport SK2 7JE.

Accepted 16 August 1983 occurred, a resistance was felt as the lung impinged on the cannula. At this stage aspiration was temporarily stopped and a few minutes were allowed for redistribution of air within the expanding lung. At the end of this time it was usually possible to aspirate a further small volume of air.

If the total volume of air aspirated reached an arbitrary figure of 4 litres and no resistance had been felt, it was assumed that no expansion had taken place and after a confirmatory radiograph had been obtained alternative treatment was initiated.

Those patients in whom the procedure was clinically successful had a confirmatory radiograph taken and were then observed in the ward for two or three days before being allowed home.

\section{Results}

Details of the 10 patients treated by this method and of the outcome are given in the table. Nine patients had spontaneous pneumothoraces and one an iatrogenic pneumothorax due to insertion of a central venous pressure line. Only two of the spontaneous group were classified as having a so called benign spontaneous pneumothorax. All of the others had a definite pathological condition of the lungs. An 81 year old man with no previous history of note had successful aspiration of a $50 \%$ right sided pneumothorax but subsequently developed a small pleural effusion on the same side, which was thought to be $N$ neoplastic in origin although there was no direct $N$ evidence. Three patients had bullous emphysema, one had had obstructive airways disease for years, and one young woman had asthma. In one patient

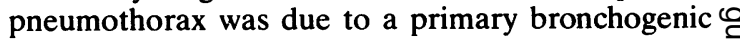
carcinoma.

Seven of the 10 patients were treated successfully? by simple aspiration. In three cases treatment was successful after one aspiration, in two cases after two aspirations (in one of these the cannula became $\stackrel{?}{q}$ blocked at the first attempt), and in two cases after $\triangle$ 
Details of 10 patients with pneumothorax treated by simple aspiration

\begin{tabular}{|c|c|c|c|c|c|}
\hline \multicolumn{6}{|c|}{ SUCCESSFUL ASPIRATION (7 patients) } \\
\hline $\operatorname{Sex}$ & Age & History & $\%$ and side & $\begin{array}{l}\text { No of } \\
\text { attempts }\end{array}$ & Recurrence and complications \\
\hline $\begin{array}{l}\text { M } \\
\mathbf{F} \\
\mathbf{F} \\
\mathbf{M} \\
\mathbf{M} \\
\mathbf{M} \\
\mathbf{F}\end{array}$ & $\begin{array}{l}81 \\
26 \\
56 \\
72 \\
30 \\
37 \\
25\end{array}$ & $\begin{array}{l}\text { None } \\
\text { Asthma } \\
4 \text { previous } \\
\text { COLD } \\
\text { None } \\
\text { None } \\
\text { Due to insertion } \\
\text { of CVP line }\end{array}$ & $\begin{array}{l}50, \mathrm{R} \\
40, \mathrm{~L} \\
40, \mathrm{R} \\
70, \mathrm{R} \\
70, \mathrm{R} \\
80, \mathrm{R} \\
80, \mathrm{R}\end{array}$ & $\begin{array}{l}1 \\
1 \\
1 \\
3 \\
2 \\
3\end{array}$ & $\begin{array}{l}\text { Pleural effusion ?neoplastic } \\
\text { None } \\
\text { Recurrence at six weeks—surgery } \\
\text { None } \\
\text { None } \\
\text { None }\end{array}$ \\
\hline
\end{tabular}

UNSUCCESSFUL ASPIRATION (3 patients)

\begin{tabular}{lllll}
\hline Sex & Age & History & $\%$ and side & Outcome \\
\hline M & 60 & None & $80, \mathrm{R}$ & $\begin{array}{l}\text { Postmortem finding: due to primary bronchogenic } \\
\text { carcinoma }\end{array}$ \\
M & 74 & COLD & $80, \mathrm{~L}$ & $\begin{array}{c}\text { Had wedge resection of emphysematous bullae } \\
\text { Treated successfully by means of an intercostal tube }\end{array}$ \\
\hline
\end{tabular}

COLD—chronic obstructive lung disease; CVP—central venous pressure.

three attempts. One patient presented with a small ipsilateral recurrence six weeks later but she had had four previous pneumothoraces and subsequently underwent pleurectomy and ligation of the bases of several bullae. None of the other pneumothoraces has so far recurred.

The three patients in whom aspiration was unsuccessful were all treated by insertion of an intercostal tube. Two achieved re-expansion of the lung. One of these had an ipsilateral recurrence one week later and proceeded to have a wedge resection of an area of bullous emphysema. The other had a large bulla at the base of his right lung that had ruptured during an airline flight, but this was successfully treated by means of an intercostal tube. The only patient who was unsuccessfully treated was the man with the primary bronchogenic carcinoma.

\section{Discussion}

The most commonly accepted initial method of treatment of pneumothorax is insertion of an intercostal tube conncected to an underwater seal, which allows gradual re-expansion of the lung. ${ }^{1}$ In the past a red rubber tube was used for this purpose, ${ }^{2}$ but recently disposable plastic ones have been used more commonly. It has been argued that irritation of the pleura by the tube causes adhesions, which should help to prevent recurrence of the pneumothorax. ${ }^{1}$ Adhesions probably occur but are less likely with a plastic tube ${ }^{2}$ and it is doubtful whether an area of adhesions over a relatively small percentage of the surface area of the lung has any effect in preventing recurrence. If the lung fails to expand then suction may be applied, but one recent study led to the conclusion that this did not have any advantage. ${ }^{3}$

One alternative to the intercostal tube and underwater seal is a drain connected to some sort of valve mechanism such as the Heimlich flutter valve, ${ }^{4}$ which is cheap and allows the patient to be mobile. Once the valve has been connected to the intercostal tube, some patients have even been treated in the outpatient department. This method has, however, failed to gain popularity, perhaps owing to mechanical problems with the valve.

Some workers by contrast advocate that most pneumothoraces can be successfully treated conservatively. ${ }^{5}$ If the pneumothorax is left alone the size will decrease by $1.25 \%$ of the total radiographic area per day, ${ }^{6}$ so that the largest may take over two months to resolve. The rate of absorption can be increased by allowing the patient to breathe oxygen in high concentration for some time.' Initial treatment of spontaneous pneumothoraces by simple aspiration is rarely mentioned in published reports. Wetzler et $a l^{8}$ refer to withdrawal of air by a "pneumothorax apparatus," and if this is unsuccessful after three attempts a red rubber tube is inserted. Horne $^{1}$ comments that aspiration of air via a needle is less commonly practised than formerly and condemns it as a first line of treatment. Klassen and Meckstroth $^{9}$ used needle aspiration in three patients, with good results in two. Stradling and Poole $^{5}$ reported treating 10 patients by simple aspiration but gave no details. Ruckley and McCormack ${ }^{10}$ reported six cases in which needle aspiration was used, but condemned this method owing to the risk of lacerating the lung and causing complications such as empyema and chronic pneumothorax. 
Inouye $e t$ al ${ }^{11}$ reported treating 22 patients successfully by "thoracocentesis," but an equal number required tube drainage for full re-expansion. More recently Raja and Lalar ${ }^{12}$ reported treating 13 patients by simple aspiration via a plastic cannula. Nine patients had successful aspiration without recurrence in the following six months.

Insertion of an intercostal tube is a traumatic, painful procedure, associated with a risk of haemothorax. If connected to an underwater seal it may confine the patient to bed, with a subsequent risk of thromboembolism. The average hospital stay of patients treated with underwater seal drains has been found to be 13 days. ${ }^{1314}$ Conservative management, although fairly reliable even in emphysematous patients, takes a long time, during which the patient's activities may be limited by exertional dyspnoea. High concentration oxygen could cause oxygen toxicity and a deterioration of pulmonary function.

Experience from this small series shows that simple aspiration of a pneumothorax with a plastic cannula is simple and non-traumatic. The procedure may be repeated-in our patients it was used up to three times. Patients have nothing to lose by having their pneumothoraces aspirated initially by this method. Treatment of both spontaneous and iatrogenic pneumothoraces by simple aspiration warrants further consideration and study.

\section{References}

${ }^{1}$ Horne NW. Spontaneous pneumothorax: diagnosis and management. Br Med J 1966;i:281-4.

${ }^{2}$ Anonymous. Spontaneous pneumothorax. Br Med J 1976;ii:1407-8.

${ }^{3}$ Sy So, Dyc Yu. Catheter drainage of spontaneous pneumothorax: suction or no suction, early or late removal. Thorax 1982;37:46-8.

${ }^{4}$ Bernstein A, Waqaruddin M, Shah M. Management of spontaneous pneumothorax using a Heimlich flutter valve. Thorax 1973;28:386-9.

5 Stradling P, Poole G. Conservative management of spontaneous pneumothorax. Thorax 1966;21:145-9.

- Gaensler EA. Parietal pleurectomy for recurrent spontaneous pneumothorax. Surg Gynec Obstet 1956;102:293-308.

${ }^{7}$ Northfield TC. Oxygen therapy for spontaneous pneumothorax. Br Med J 1971;iv:86-8.

${ }^{8}$ Wetzler K, Preisler B, Schilling W. [Spontaneous pneumothorax as an urgent internal problem.] $Z$ Gesamte Inn Med 1975;30:194-6.

${ }^{9}$ Klassen KP, Meckstroth CV. Treatment of spontaneous pneumothorax. JAMA 1962;182:1-5.

${ }^{10}$ Ruckley CV, McCormack RJM. The management of spontaneous pneumothorax. Thorax 1966;21:139-44.

"Inouye WY, Berggren RB, Johnson J. Spontaneous pneumothorax: treatment and mortality. Dis Chest 1967;51:67-73.

12 Raja OG, Lalar AJ. Simple aspiration of spontaneous pneumothorax. Br J Dis Chest 1981;75:207-8.

${ }^{13}$ Smith WG, Rothwell PPG. Treatment of spontaneous pneumothorax. Thorax 1962;17:342-9.

${ }^{14}$ Thompson HT, Bailey RR. Management of spontaneous pneumothorax. NZ Med J 1966;65:101-4. 